Vol. 1, No. 2, 2020

Ivanna Gits, Mykola Zhuk, Halyna Pivtorak

Lviv Polytechnic National University

12, Stepan Bandery Str. Lviv, 79000, Ukraine

(C) I. Gits, M. Zhuk, H. Pivtorak, 2020

https://doi.org/10.23939/tt2020.02.057

\title{
ANALYSIS OF DEMAND FOR PUBLIC TRANSPORT SERVICE IN LVIV CITY
}

Summary. The demand for public transport on the example of Lviv city is analyzed in the paper. The aim of the trip, the duration of the trip, vehicle occupancy rate, walking approach to the stop, and the choice of public transport mode are determined as the main impact factors. The questioning of 1100 users of public transport is carried out. During the formation of transport strategy of public transport system functioning in large cities, it is necessary to consider such factors of functioning as optimal, from the view of transport provision, location of places of work and study, trips are up to $45 \mathrm{~min}$; vehicle occupation rate is up to $80 \%$ (on the most routes); the walking distance is up to $600 \mathrm{~m}$; vehicles of large capacity.

The provision of these indicators in transport systems will provide an opportunity to increase the effectiveness and enlarge the demand for public transport services as a result of qualitative functioning.

Key words: demand for public transport, the aim of the trip, trip duration, the comfort of the trip, walking approach.

\section{INTRODUCTION}

Transportation is one of the priority needs of human life. Criteria that have a direct impact on the choice of one or another transport mode are important from the view of the determination of transportation demand. Authors [1] review these impact criteria in the form of a hierarchical pyramid (4 levels) with the distribution of them by the primary and secondary (Fig. 1).

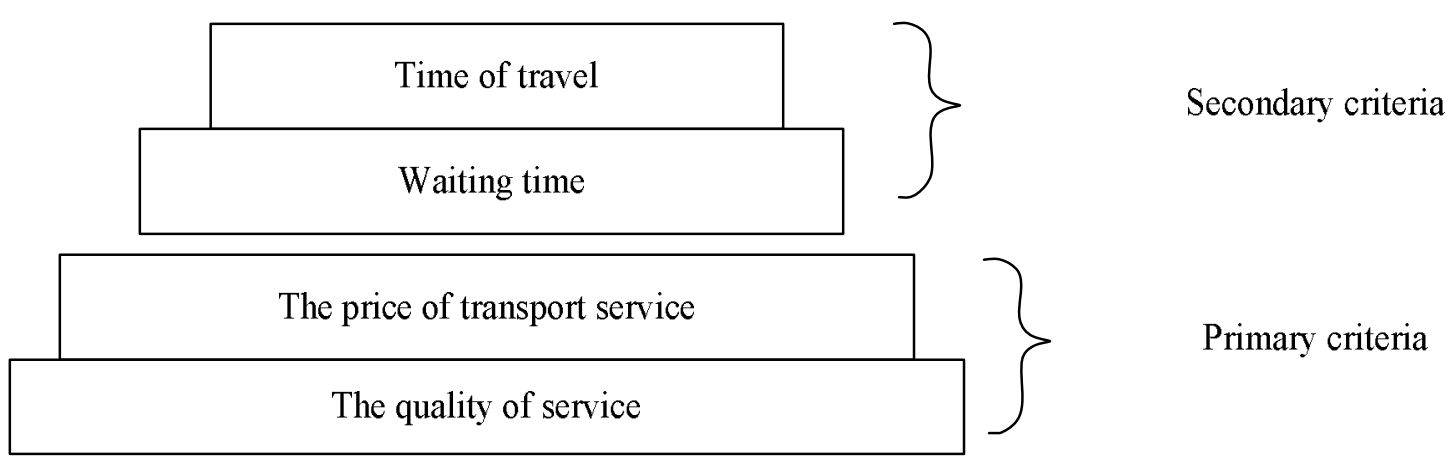

Fig. 1. Primary and secondary criteria for choosing the mode of public transport

The quality of service is at the basis of the pyramid. Passengers, in modern conditions, need to know whether the services for which they pay are qualitative. The price of the service is in the second place because, if the service is of poor quality then the passenger thinks whether it is worth paying for it or he should search for alternative ways of transportation. Waiting time and trip time are the secondary criteria. 
The level of demand for passenger transportation is conditioned [2]:

- planning structure of the city in the whole and separate objects of residential, trade, production, and social spheres;

- the condition of city economics, taking into account such indicators as the number of workplaces, location of centers of work and social activities;

- the real motorization level of the population.

The problems of urban public transport effective functioning in Ukraine in recent years not only were not solved but became in a critical state. Today, the general development of the road networks does not comply with the modern pace of city motorization. The high traffic intensity, the absence of bypass roads, and transport junctions both within the city and outside it caused the critically low level of capacity of the main arterial roads and large traffic jams in peak periods.

The effective provision of determining the level of public transport services demands marketing research on studying and meeting all needs and wishes of consumers. The criteria of passenger transport service quality include rhythmicality, regularity, and the speed of transportation, travel safety, convenience in time of departure and arrival, compliance of the services to the demands.

If passengers have negative thoughts about the given mode of transport as a consequence of dissatisfaction with the requirements, then is "loses credibility" and loses the competition to the other modes of transport.

\section{RESEARCH STATEMENT}

Impact factors on the urban public transport system functioning are sufficiently described in scientific resources. But, the level of this impact differs depending on the planning features of the specific city territory, city population structure, etc. That is why the understanding of the interrelation of these factors will contribute to better planning of urban transport system operation.

The aim of this study is the analysis of the demand for public transport services under the influence of different factors (subjective and objective).

To fulfill the set aim, it is necessary to solve such tasks:

- determination of the subjective and objective factors which have the largest impact on public transport demand;

- carry out the questionnaire research (questioning the public transport users in Lviv city at the stops and online questioning with the use of Google Forms);

- carry out the analysis of the demand for public transport services by defined impact factors.

\section{ANALYSIS OF IMPACT FACTORS ON PUBLIC TRANSPORT DEMAND IN LVIV CITY}

Daily trips, such as a trip to work or study places, have a fixed time of departure and arrival. These trips are mostly repetitive and planned which facilitates the people of making more justified decisions about choosing the transport. To increase the demand for public transport, it is necessary to base on the needs of travelers, the quality of passenger transport service, time for travel, and getting to/from the stop [3]. The last decades show significant growth in private transport usage. If before such trips were made mainly outside the city or for long distances, then today significant transportation volumes are for city travel. But, the share of public transport in this growth is insignificant. The attractiveness of public transport does not increase but, vice versa reduces. Old vehicles, uncomfortable and expensive trips, long waiting times of public transport, imperfect routes, and many other factors have a negative impact on the demand for public transport.

For the provision of public transport attractiveness, it is necessary to pay attention to disembarrassment of the trip and transportation effectiveness (too crowded buses during peak hours and almost empty at other times). 
The reduction of the use of the private vehicle during the trips within the settlement provides, in the near future, the formation of the modern transport policy which has an aim to increase the effectiveness of urban transport complex functioning, improvement of the methods and means for its management, in particular, implementation of the elements of transport logistics and methods of demand management for transport services [4].

The objective impact factors the demand for transport services users are economic, social, and natural [5]:

- economic factors reflect economic stability of the country (inflation rate), location of the production and productive forces, development of social production in the whole country and separate fields (for example, tourism development), and actual income level of the population;

- social factors include the stability of the social and political state of the regions and the whole country, population growth, structure of the population by profession and its distribution by residence (in cities and villages), change in the distribution of population in time and space, migration, development of material and cultural level of population life (the level of education and the culture of the population), national, religion, local and traditional habits (consumer tastes);

- natural factors: climate, amount of rainfall, terrain, ecological safety of regions, etc.

Subjective impact factors are [5]:

- presence of different transport modes, the price of the travel and the level of transportation quality, the level and the nature of competition on the transport market;

- paying capacity of passengers, on which such factors have an impact as the price (tariff), the quality of passenger service, and the variety of services on particular transport mode.

Dimensions of demand for transport services are determined by the nature and the number of spatial connections between those who provide these services and consumers. From the characteristics of the location of potential demand places arise specific needs in transportation. In most cases, for the proper organization of this process, it is necessary to carry out field research that demands significant time and money consumption.

As authors [6] consider, transportation by public transport can be increased by lowering the price for the travel. Also, in their opinion, density, availability of destination points, distances to the central business districts, and demographic features of passengers have an impact on public transport demand. Authors [7] note that the number of trips directly depends on the different needs of the population with the use of public transport, herewith trips from home to study/work and then back have permanent nature and are the most compulsory, besides, people have to travel to visit cultural and recreational centers.

In the paper [8], the analysis of the question of why in Germany public transport is more successful than in the USA and why Germans use it in 5 times more than Americans is given. The conclusions were such that in Germany the success of public transport is conditioned by:

- more qualitative service;

- attractive tariffs and more convenient way of tickets purchasing;

- full multimodal and regional integration;

- high taxes and restriction of car usage;

- the policy of wide routes and convenient transfers between transport modes.

To encourage private transport owners of usage the public transport, the range of factors is needed, as given in the study [9]:

- reliability and frequency of service;

- lowering the tariffs on the travel;

- parking policy in business centers.

Apparently, today every driver faces the problem of parking as parking lots mostly cannot contain all necessary amount of transport, and the perspective that you will quickly and efficiently travel to the destination point and at the end of the day travel back saving time and money will force many to change their minds. 
Paper [10] is connected with the formation of the function of the attractiveness of distance from home to work using public transport in Kharkiv. The attributes of the effectiveness function are travel duration, bus occupancy rate, the price of the trip, and the number of transfers. Work trips are reviewed in this study which, obviously are the most massive. But for the cities with a significant rate of students in the structure of the population, the study of the peculiarities of their behavior during the choosing of the way of transportation is important.

Conducted research [11] visualize the travel by public transport as time distance and the number of necessary transfers during the trip. It depends on the facts, whether the user has the schedule of the trip and specific time losses on it, or the trip is spontaneous and has unexpected nature.

In the study [12], it is stated that the crowding on public transport stops, and further in transport, has a significant impact on public transport demand. Authors indicate that if the demand for public transport is evaluated without considering people crowding, then it will be exaggerated.

Apparently, to everyone, using public transport would be convenient leaving the house to get to the public transport stop immediately. In the publication [13], the research of how walking distance to public transport stop influence its usage is carried out. It is determined that a large distance from the stop often is one of the reasons which limit more often usage of public transport. Demographic characteristics (age, sex, a child in the family) and availability of own car also have an impact.

To make public transport more attractive, such factors as fare, movement intervals, bus size and the number of seats should be considered. Author [14] shows that, in comparison with previous years, people use public transport more often. The author explains that ecological consciousness, increase of public transport services quality, and the high cost of private car usage forwarded people to public transport usage.

Research of comfort level from trips is given in paper [15]. In this research, there was established that such factors as trip duration and vehicle choice have a significant impact on satisfaction from the trip.

Determination of criteria of transport mode choose exactly for city transportation and the assessment of these criteria on the choice of transport mode, depending on the trip conditions is the component of determining the demand for passenger transportation. Consideration of choice of transport as trip characteristics and external transport junctions' characteristics during the formation of the effectiveness function will allow studying the mutual influence of these factors on the attractiveness of one or another transportation mode[10].

To determine the subjective and objective factors of demand for public transport in Lviv city, the questionnaire of public transport users was carried out. Lviv is the city with a population of 760 thousand people and an area of 182 square kilometers. The number of students, by statistical data, is about 120 thousand, i.e. $16 \%$ from the number of citizens, and the number of working people is about 244.4 thousand, i.e. $32 \%$ [16].

The main impact factors in questionnaires were defined:

- the aim of the trip (A),

- the duration of the trip (B),

- vehicle occupancy rate $(\mathrm{C})$,

- $\quad$ walking distance to the stop, and the mode of public transport for the trip (if available) (D).

The questionnaire was carried out both at public transport stops and online (with the use of Google Forms). In general, the sample was 1100 questionnaires. The research was conducted in October and November 2019. The respondents were public transport users in different districts of Lviv city. The age category of users during the questionnaire on public transport stops was within 17-70 years. In questionnaires, received with the use of Google Forms, the age category and also place of residence and routes which are used by respondents were not determined. During the determination of the aim of the travel, the most respondents on the stops pointed "work" and "shopping" and during the questioning with Google forms, most respondents pointed "study". From the given aforesaid, we can conclude that questionnaire results with Google Forms were obtained mostly from pupils and students.Having analyzed the questionnaire, we obtained such results: 
A) The number of trips depending on the aim (Table 1):

- most trips were made to the places of study - $34 \%$ (among them, $7 \%$ needed transfers);

- $20 \%$ of respondents traveled to the places of work (among them, $7 \%$ transferred to another transport mode or route);

- $\quad 17 \%$ of respondents traveled to the places of shopping (among them, almost $4 \%$ with transfers);

- $29 \%$ of trips were made with other aims.

Trips depending on their aim

\begin{tabular}{|c|c|c|}
\hline The aim of the trip & Number of transport services users & With transfers \\
\hline Study & 370 & 26 \\
\hline Work & 220 & 15 \\
\hline Shopping & 190 & 7 \\
\hline Other & 320 & 0 \\
\hline
\end{tabular}

Transport services users who traveled with transfers were made to choose the same route because the trip to the place of work or study is fixed-timed and necessary but the alternative to go by one mode of transport is absent. It increases the expenditure of time and money of the consumer and, therefore, public transport loses its attractiveness.

B) From the investigation of the time of travel to necessary place (Fig. 2), it is established that $42 \%$ of respondents consider the time of the travel to the destination point in 15-30 min as optimal, more $36 \%$ consider that this time is $30-45 \mathrm{~min}$. This is because there are many routes in Lviv city which are diametric. They go from the dormitory districts to the places of work and study which are located at the opposite end of the city. Only $7 \%$ prefer public transport with a trip of less than $15 \mathrm{~min}$, as in such trip services users will prefer walking rather than waiting for public transport. Only in $15 \%$ of respondents, the duration of the trip is 45-60 min. During such trip duration (45-60 min and more), public transport loses its attractiveness and users choose another type of transportation (personal car, aggregators of taxi services).

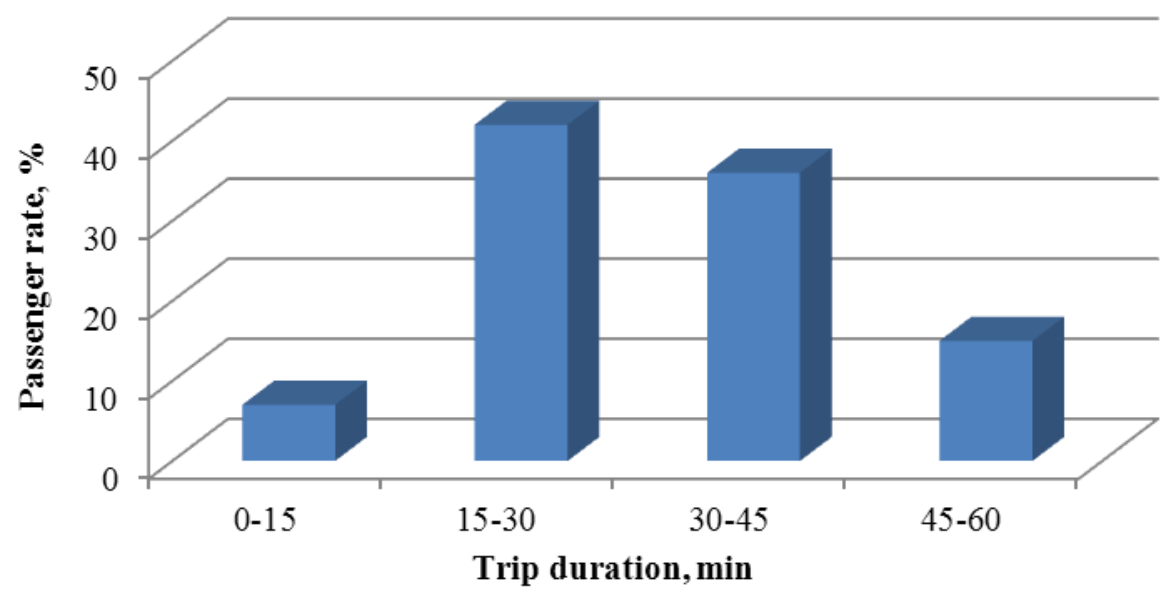

Fig. 2. Structure of the demand for public transport services depending on the trip duration

C) One more factor which has an impact on the demand for public transport is travel comfort. We accepted the travel comfort as the occupancy rate of the vehicle. Respondents during the assessment of the travel comfort level indicated such occupancy rates of vehicle:

- there are free seats $(20 \%)$;

- all seats are occupied (40\%); 
- all seats are occupied; the number of standing passengers is no more than a half of cabin $(60 \%)$;

- all seats are occupied; the number of standing passengers is close to the maximum but it comfortable to stand (60\%);

- crowding in the cabin (100\%).

There is given in Fig. 3 that the main share of respondents (41\%) makes trips with the vehicle occupancy rate by $80 \%$. The least number of passengers (3\%) traveled with a bus occupancy rate of $20 \%$ which can be caused by the start of the travel or its unpopularity.

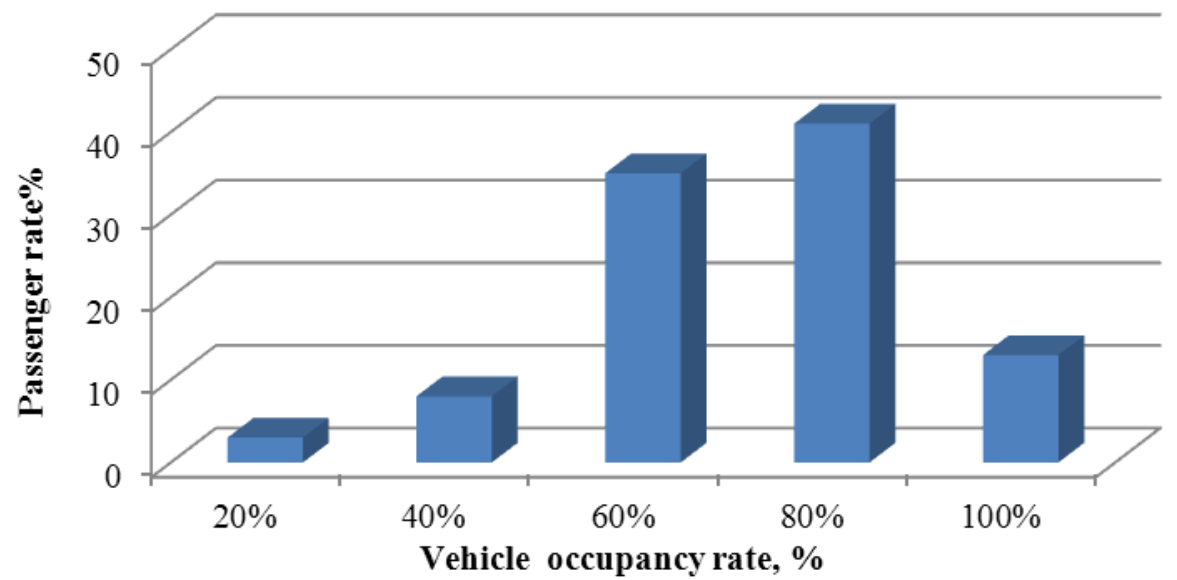

Fig. 3. Structure of demand for public transport services depending on the travel comfort (vehicle occupancy rate)

D) Walking distance to the public transport system is one the impact factors on the services as, besides trip duration, time spent on the approach to the public transport stop influence the general time to the destination point. In the proposed questionnaire, respondents pointed the distance to the public transport stop from 200 to $1000 \mathrm{~m}$. The majority of respondents (42\%) pointed out the walking distance up to $200 \mathrm{~m}$ (Fig. 4) and only $6 \%$ of respondents every time walk 800-1000 m. In such large walking distance services users rather will choose another transport mode (personal car, aggregators of taxi services).

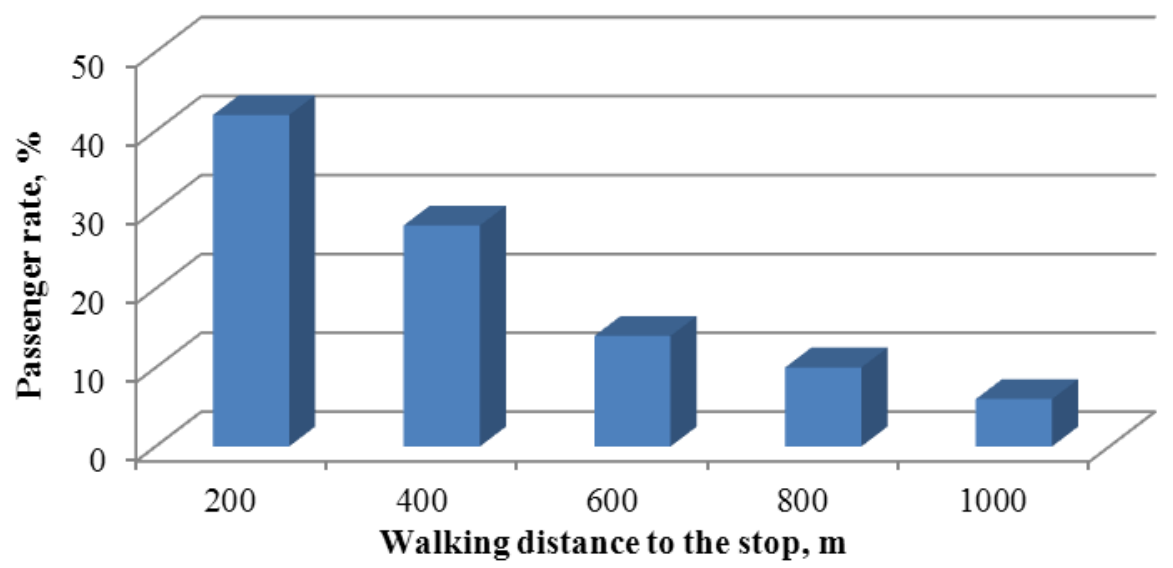

Fig. 4. The structure of demand for public transport services depending on the distance from walking distance to the stop

E) In Lviv city, public transport services are provided by large buses (by capacity up to 100 passengers), small buses (by capacity up to 43 passengers), trolleybuses, and trams. If possible, the user can choose a different transport mode. In the questionnaire, respondents indicated the mode of transport which they use 
in the presence. Most frequently in Lviv city citizens use large buses (Fig. 5) as this type of vehicle now is widespread; also these buses are new and low-floor. The rate of trolleybus and tram users is $18 \%$ and $16 \%$ respectively. It can be explained by a fixed network of tram and trolleybus routes.

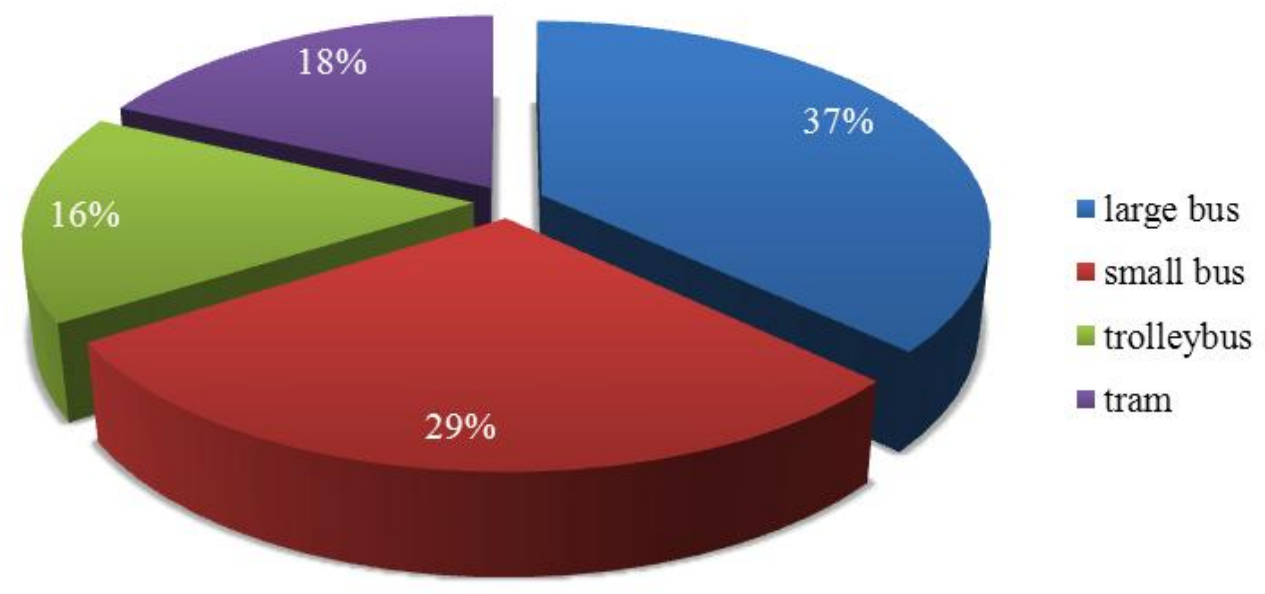

Fig. 5. Choose of transport mode by services user (if possible)

Having analyzed five impact factors of public transport services, we can say about their importance within certain values. In particular, trips in the duration of 15-45 min are effective enough in Lviv city.

\section{CONCLUSIONS AND RESEARCH PERSPECTIVES}

For today, the assessment of the demand for public transport is quite important. For the objective assessment of demand for public transport, credible data about the behavior of public transport users are needed. More qualitative functioning of the public transport system will increase the number of users. In conducted research, qualitative values of impact factors on the demand for public transport. The main of them are:

- the aim of the trip;

- the duration of the trip;

- vehicle occupancy rate (trip comfort);

- walking distance to the public transport system;

- choose public transport mode (if possible).

By the aim of the trip (A), trips to the places of work and study are necessary. By the results of the questionnaire, it is established that such trips are $54 \%$.

The duration of the trip (B) is determined as optimal within 15-45 min (such trips are $77 \%$ ). Users consider comfort trip (C) within the occupancy rate no more than $80 \%$. Walking distance (D) for public transport system users in Lviv city is enough for usage and is in the range up to $600 \mathrm{~m}$ (84 \%). Concerning the type of public transport (E), users prefer vehicles with high capacity (71\%).

During the formation of the transport strategy of the public transport system in large cities, it is necessary to consider such indicators of functioning:

- optimal, from the view of transport provision, location of places of work and study;

- transport trips - up to $45 \mathrm{~min}$;

- vehicle occupancy up to $80 \%$ (on the vast majority of routes);

- walking distance is up to $600 \mathrm{~m}$;

- vehicles with high capacity. 
The provision of these indicators in transport systems will provide an opportunity to increase the effectiveness and enlarge the demand for public transport services by its qualitative functioning.

\section{References}

1. Hryniv N., Podvalna H., (2015) Transport services as an object of analysis and management. Journal of Lviv Polytechnic National University. Series of Economics and Management Issues Volume 2 Number 815 (1). 27-35 (in Ukrainian).

2. Hryhorova T. M., Davidich YU. O., Dolya V. K. (2015). Estimation of elasticity of demand at the service of suburban passenger car transport. Technology audit and production reserves, Volume 3/3(23). 13-16. doi: 10.15587/2312-8372.2015.44769 (in Ukrainian).

3. Owczarzak Ł., Żak J. (2015). Design of Passenger Public Transportation Solutions Based on Autonomous Vehicles and Their Multiple Criteria Comparison with Traditional Forms of Passenger Transportation. Transportation Research Procedia Volume 10, 472-482. doi: 10.1016/j.trpro.2015.09.001 (in English).

4. Krueger R., Rashidi T.,Rose J. M. (2016). Preferences for shared autonomous vehicles Transportation Research Part C: Emerging Technologies, Volume 69. 343-355 (in English).

5. Zherdyev M.D. Myroshnychenko Yu.V. (2010) The influence of transport service quality on demand of consumers of transport services. The bulletin of transport and industry economics Volume 29. 250-253 (in Ukrainian).

6. Liu Ya., Wang S., Xie B. (2019). Evaluating the effects of public transport fare policy change together with built and non-built environment features on ridership: The case in South East Queensland, Australia. Transport Policy, Volume 76, 78-89. doi: 10.1016/j.tranpol.2019.02.004 (in English).

7. Krystopchuk M. Y., \& Lobashov O. O. (2012). Suburban passengers transportation. Kharkiv: NTMT (in Ukrainian).

8. Buehler R., Pucher J. (2012). Demand for Public Transport in Germany and the USA: An Analysis of Rider Characteristics. Transport Reviews Volume 32, Issue 5, 541-567. doi: 10.1080/01441647.2012.707695 (in English).

9. Redman L., Friman M., Gärling T., Hartig T. (2013). Attributes of public transport quality that attract car users: A review of the study. Transport Policy Volume 25, 119-127. doi: 10.1016/j.tranpol.2012.11.005 (in English).

10. Zhuk M., Pivtorak H., Kovalyshyn V., Gits I. (2020) Development of a multinomial logit-model to choose a transportation mode for intercity travel. Eastern-European Journal of Enterprise Technologies, Volume 3/3 (105).69-77 (in English).

11. Kujala R., Weckström C., Mladenović M., Saramäki J. (2018). Travel times and transfers in public transport: Comprehensive accessibility analysis based on Pareto-optimal journeys. Computers, Environment and Urban Systems Volume 67, 41-54. doi: 10.1016/j.compenvurbsys.2017.08.012 (in English).

12. Tirachini A., .Hensher D. A, Rose J. M. (2013). Crowding in public transport systems: effects on users, operation and implications for the estimation of demand, Transportation Research Part A: Policy and Practice, Volume 53, 36-52. doi: 10.1016/j.tra.2013.06.005 (in English).

13. Ivan I., Horák J., Zajíčková L., Burian J., Fojtík D. (2019). Factors Influencing Walking Distance to the Preferred Public Transport Stop in selected urban centres of Czechia. GeoScape Volume 13: Issue 1, 16-30. doi: 10.2478/geosc-2019-0002 (in English).

14. Tirachini A., Hensher D. A., Rose J. M. (2014). Multimodal prices and optimal design of urban public transport: the interaction between traffic congestion and bus congestion. Transportation Research Part B: Methodological, Volume 61, 33-54. doi: 10.1016/j.trb.2014.01.003 (in English).

15. Yanovs kyy P. O. (2015) The general description of the key factors that determine volumes and structure of passenger traffic. Transport systems and transportation technologies. Volume 10. 117-124 (in Ukrainian).

16. Main Statistical Office in Lviv Region: Retrieved from https://www.lv.ukrstat.gov.ua/ukr/themes/09/theme 09.php?code=9. (in Ukrainian).

Received 02.07.2020; Accepted in revised form 11.09.2020. 